\title{
Has the EU Incentive for Drug Repositioning Been Effective? An Empirical Analysis of the "+1" Regulatory Exclusivity
}

\author{
Johnathon Liddicoat • Kathleen Liddell • \\ Mateo Aboy $\cdot$ Jakob Wested
}

Accepted: 1 July 2021 / Published online: 20 July 2021

(C) The Author(s) 2021

\begin{abstract}
EU law incentivises drug marketing authorisation holders (MAHs) to find new uses for their compounds (research known as "repositioning") by offering them an extra year of market protection if the new use is authorised. This extra year, known as the " +1 ", was enacted on limited evidence, and no study has examined its effect since it began. Yet, several leading commentators suggest lengthening the +1 . This study assesses the effectiveness of the +1 by analysing all the relevant instances of MAHs repositioning their drugs before and after the +1 came into effect. The results show that: (i) $42.2 \%$ of MAHs repositioned their drugs before the +1 came into effect, and (ii) once the +1 did come into effect, it did not increase the percentage of MAHs that repositioned their drugs. This study finds that the +1 failed to increase repositioning and then proceeds to consider reform options, including repealing the law. In doing so, this study takes the first steps towards an evidence-based policy for the topic.
\end{abstract}

\footnotetext{
J. Liddicoat $(\bowtie)$

Senior Research Associate, Centre for Law, Medicine, and Life Sciences, Faculty of Law, University of Cambridge, Cambridge, UK

e-mail: je168@cam.ac.uk

\section{K. Liddell}

Director, Centre for Law, Medicine, and Life Sciences, Faculty of Law, University of Cambridge, Cambridge, UK
}

\section{Aboy}

Principal Research Scholar, Centre for Law, Medicine, and Life Sciences, Faculty of Law, University of Cambridge, Cambridge, UK

\section{J. Wested}

Industrial Postdoc, Centre for Advanced Studies in Biomedical Innovation Law, Faculty of Law \& Danish Medicines Agency's Data Analytics Center, University of Copenhagen / Danish Medicines Agency, Copenhagen, Denmark 
Keywords Drug repositioning $\cdot$ Regulatory exclusivities $\cdot$ Patents $\cdot$ Empirical study

- Intellectual property

\section{Introduction}

Before a company can market a therapeutic drug in the EEA, the company must receive a marketing authorisation (MA) from a regulatory authority. ${ }^{1}$ Companies that hold MAs are known as marketing authorisation holders (MAHs), and a company can obtain an EEA-wide MA through one application to the European Medicines Agency (EMA) via what is called the "centralised procedure". ${ }^{2}$ If an MAH then develops a new medical use for its drug, research commonly known as "repositioning", then the MAH must obtain a second MA for the repositioned use from the EMA.

Repositioning has several advantages over developing new drug compounds. Perhaps the most noticeable are that it is faster and cheaper. ${ }^{3}$ Drug industry supplied data indicate the risk-adjusted average cost of developing a new compound is around US\$1.4 billion, ${ }^{4}$ whereas drug repositioning is estimated to cost 40 to $90 \%$ less. ${ }^{5}$ Drug repositioning is typically safer, too, because information already exists about the drug's toxicity from clinical trials and clinical use. ${ }^{6}$ Consequently, governments and drug companies are attracted to drug repositioning, yet the situation is not that simple: commentators argue that EU law insufficiently incentivises it. ${ }^{7}$

Two intellectual property (IP) regimes incentivise drug repositioning: patents and regulatory exclusivities. ${ }^{8}$ Although both regimes provide incentives for repositioning, commentators contend they are insufficient and that reform to either, or both, is needed. ${ }^{9}$ Policy developments are challenging, however, because there is a fine line between exclusive rights that appropriately incentivise innovators and exclusive rights that unduly restrict competition.

\footnotetext{
${ }^{1}$ Directive (2001/83) on the Community code relating to medicinal products for human use [2004] OJ L311/67, Art. 6(1).

${ }^{2}$ Regulation 726/04 laying down Community procedures for the authorisation and supervision of medicinal products for human and veterinary use and establishing the European Medicines Agency [2004] OJ L136/1, Art. 5(2).

3 Ashburn and Thor (2004), p. 673

${ }^{4}$ DiMasi et al. (2016), p. 26. Though, it should be noted that this figure has been criticised, see e.g. Prasad and Mailankody (2017), pp. 1570 and 1572-1574.

${ }^{5}$ Grabowski and Moe (2008), p. 85; Sahoo (2007), p. 28; Allergan Inc (2011), p. 8; Nosengo (2016), p. 315; see also DiMasi et al. (2016), pp. 26-27.

${ }^{6}$ Oprea and Mestres (2012), p. 759.

${ }^{7}$ See e.g. Cordery and Willis (2017), p. 25; Breckenridge and Jacob (2019), p. 2. This issue is examined further in the Background.

${ }^{8}$ Regulatory exclusivities are not always thought of as IP, but pharmaceutical law experts typically classify them as such, see e.g. Feldman (2018), p. 593; Feldman (2016), pp. 54-55; Manley and Vickers (2015), p. 301.

${ }^{9}$ See e.g. Cordery and Willis (2017), p. 27; Breckenridge and Jacob (2019), p. 2. This issue is examined further in the Background.
} 
This study focuses on drugs authorised via the centralised procedure and examines the effectiveness of the regulatory exclusivity designed to incentivise MAHs to reposition their drugs. This incentive is only available for MAHs that receive a primary MA under Art. 8(3) of Directive 2001/83. Article 8(3) MA applications are known as "full self-standing applications", ${ }^{10}$ and must include the results of clinical trials, amongst other evidence. ${ }^{11}$ When an MAH initially obtains an Art. 8(3) MA, it receives 10 years of market protection, and, in brief, if it repositions the drug within eight years, it is eligible for an extra year of market protection. $^{12}$ This extra year of market protection is commonly known in the industry as “+1".

Market protection holds off competitive pricing by preventing the EMA (and other European regulatory agencies) from authorising generic and biosimilar versions of the drugs (collectively referred to as "generics" unless otherwise indicated). ${ }^{13}$ Generics have shorter routes to market because the applications to regulators are based to a large extent on safety and efficacy data generated when the drug is first authorised. ${ }^{14}$ The extension of market protection means the MAH can keep drug prices high for longer, potentially costing governments millions of euros per year. ${ }^{15}$ Yet, the introduction of the +1 was made based on limited evidence, ${ }^{16}$ and no study has examined its effectiveness since it commenced in $2005 .{ }^{17} \mathrm{~A}$ review of the effectiveness of the regulatory exclusivity is overdue, especially given that leading commentators have raised the idea of lengthening the exclusivity to enhance incentives for repositioning. ${ }^{18}$ The past few decades have also witnessed an increase in the duration and breadth of regulatory IP rights for drugs in Europe. ${ }^{19}$

This study assesses the effectiveness of the +1 by analysing all the instances of MAHs repositioning their drugs before and after the +1 came into effect. More specifically, this study aims to answer whether the +1 has increased: (i) the

\footnotetext{
${ }^{10}$ Manley and Amos (2015), p. 97.

${ }^{11}$ Directive (2001/83), Art. 8(3)(i).

12 Regulation 726/04, Art. 14(11); Directive (2001/83), Arts. 8(3) and 10(1).

13 Directive (2001/83), Art. 10(1).

${ }^{14}$ Directive (2001/83), Art. 10(1).

15 Berndt and Aitken (2011), pp. 195-197; United States Food \& Drug Administration (2018); Nayroles (2017), pp. 7-9. The extension of market protection can assist companies' "evergreening" strategies, but this is a complex topic that requires careful study, see Lietzan (2019), p. 867.

${ }^{16}$ CMS Cameron McKenna and Andersen Consulting (2000), p. 18.

${ }^{17}$ Halabi (2018), p. 30. That said, other studies have tackled related but different issues, see e.g. Langedijk et al. (2016), p. 348.

${ }^{18}$ Breckenridge and Jacob (2019), p. 2; Cordery and Willis (2017), p. 27; Nayroles (2017), pp. 12-13; Horgan (2018), p. 25.

${ }^{19}$ E.g. supplementary patent certificates were introduced in 1992 (Regulation 1768/92 concerning the creation of a supplementary protection certificate for medicinal products [1992] OJ L182/1); and data protection for drugs was introduced in 1987, which gave Member States the option of providing six or ten years of protection (Directive 87/21 amending Directive 65/65/EEC on the approximation of provisions laid down by law, regulation or administrative action relating to proprietary medicinal products [1987] OJ L15/36, Art. 1(iii)). This system of data protection was replaced in 2005 with eight years of data protection and two years of market protection, which was compulsory in all Member States (Regulation 726/04, Art. 14(11)).
} 
proportion of drugs repositioned by MAHs, or (ii) the number of times drugs are repositioned by MAHs, as drugs are often repositioned more than once. A drug is counted for the purposes of this study if an MAH obtained a primary MA under Art. 8(3) (or antecedent legislation) via the centralised procedure. And a drug is counted as repositioned if the new use was authorised within eight years of the primary MA. The eight-year period is one of the eligibility criteria for the +1 .

This paper is organised as follows. The first part provides background on drug repositioning and IP regimes, including detail on regulatory exclusivities, patent law, and drug authorisation processes. The second part describes how this study assembled and sorted drug authorisation data. The third part analyses the data, showing that repositioning did not increase after the +1 came into effect. The fourth part addresses the policy implications flowing from this study. Contrary to commentators' opinions, this study does not find evidence indicating the EU should lengthen the +1 . To conclude, this paper describes additional research to determine the appropriate policy response, including whether the +1 should be repealed; a plausible proposal based on this study's findings that the +1 did not increase repositioning.

\section{Background and Study Aims}

\subsection{Terminology}

The terminology used to describe research on new uses of known drugs varies and can be confusing. ${ }^{20}$ This study uses the term repositioning in a specific way, referring to the development of new uses, or more technically, new medical indications, for already authorised drugs. The +1 is only available for MAHs that already hold an MA for a drug; thus, this study focusses only on repositioning by MAHs. By contrast, drug "rescuing" is often used to describe developing a drug for an indication after the drug was unsuccessfully developed for a different indication. This study does not address rescuing.

\subsection{Regulatory Exclusivities}

The prospect of selling government-authorised drugs in a competitive marketplace without IP is generally regarded as an insufficient incentive for drug development because competitors might copy the innovator's product and sell it at a cheaper price, having incurred fewer development costs. Regulatory exclusivities and patents award developers exclusive rights to market drugs for a period of time, thereby improving the economic incentives.

This study evaluates the effectiveness of the +1 by comparing the effect of the current regulatory regime with the regime it replaced. Therefore, it is necessary to describe the replaced regime: Art. 4(8)(a)(iii) of Directive 65/65 provided 10 years of data protection for all products authorised by the EMA through the centralised

\footnotetext{
${ }^{20}$ For an overview, see Langedijk et al. (2015), p. 1027.
} 
procedure when it began in $1995 .^{21}$ This system continued under Directive 2001/83, ${ }^{22}$ which superseded Directive 65/65, and did not include an exclusivity for repositioning. 23

Regulation 726/2004, which ushered in the current regulatory regime, introduced various changes. ${ }^{24}$ First, Art. 14(11) replaced the 10 years of data protection with eight years of data protection that runs concurrently with 10 years of market protection. "Data protection" (commonly called "data exclusivity") refers to a time period in which competitors cannot apply for authorisations of generics. ${ }^{25}$ Market protection (commonly called "market exclusivity") is different; it refers to a time that competitors can obtain authorisations of generics, but the generic cannot be placed on the market until the market protection concludes. ${ }^{26}$

Regulation 726/2004 also introduced an extension to market protection for repositioning. Article 14(11) states that market protection

shall be extended to a maximum of 11 years if, during the first eight years of those ten years, the marketing authorisation holder obtains an authorisation for one or more new therapeutic indications which, during the scientific evaluation prior to their authorisation, are held to bring a significant clinical benefit in comparison with existing therapies.

The exclusivity periods described by Regulation 726/2004 are commonly known by the formula " $8+2(+1) ",{ }^{27}$ which this study adopts, but this formula requires an explanation to avoid confusion. The +2 refers to the 10 -year market protection and " 2 " is used instead of " 10 " because it is pointing to the fact that market protection eclipses data protection by two years. The +1 refers to the extra year of market protection for repositioning, however, it should be noted that the +1 is not automatically granted like data protection and market protection. Rather, MAHs must apply for the +1 when they submit their application to reposition a drug, including information on how the drug meets the "significant clinical benefit" test. $^{28}$

A common perception of repositioning is that it involves the authorisation of a drug to treat a second disease or condition. However, this view is too narrow.

\footnotetext{
${ }^{21}$ Directive 65/65 on the approximation of provisions laid down by Law, Regulation or Administrative Action relating to proprietary medicinal products [1965] OJ 369/22, Art. 4(8)(a)(iii); Manley and Strachan (2015), p. 258.

22 Directive (2001/83), Art. 10(1)(a)(iii) (repealed).

23 R. $v$ The Medicines Control Agency (C-368/96) EU:C:1998:583; [1998] E.C.R. I-7967; [1999] 2 C.M.LR. 181 at [38]-[53].

24 The regulatory exclusivities are mirrored in Directive (2001/83), Art. 10(1).

25 Regulation 726/04, Art. 14(11); Directive (2001/83), Art. 10(1); European Commission (2015), p. 39. Article 14(11) also removed the option for Member States to choose the duration of market exclusivity, meaning some Member States now provided lengthened market protection. This lengthened market protection may have increased repositioning at the Member State level.

26 European Commission (2015), pp. 39-40.

27 See e.g. Manley and Strachan (2015), p. 259; European Medicines Agency, Generic and Hybrid Medicines, p. 15.

28 See generally European Commission (2007), pp. 5-6; European Commission (2006), p. 16.
} 
Authorised indications are often limited by factors such as age, disease severity or duration of treatment, ${ }^{29}$ and the EMA defines "new therapeutic indication" in Art. 14(11) to mean any expanded use of an authorised drug. Consequently, MAHs can obtain the +1 for repositioning that, for example, expands the age range of patients who have the same condition. ${ }^{30}$

\subsection{Patents}

The issue of whether the +1 has incentivised drug repositioning has gained prominence in recent years. This prominence is due to many experts, including practising lawyers, scientists, academics and a former judge, arguing that patents insufficiently incentivise it. They argue that patents for repositioned indications, commonly known as "second medical use" patents, ${ }^{31}$ can be: (i) impossible to obtain; (ii) difficult to obtain; (iii) possibly invalid and therefore prone to revocation; and (iv) difficult to enforce. ${ }^{32}$

Patents for repositioned drugs are impossible or difficult to obtain because of the requirements that patent applications must meet to be granted and avoid revocation. Patents are only valid for novel inventions (not previously available to the public). ${ }^{33}$ Consequently, patents for repositioned drugs might be impossible or difficult to obtain, or revocable, because treating the new indication is already described in scientific literature. ${ }^{34}$ Another requirement for a valid patent is that the invention involves an inventive step, ${ }^{35}$ which requires that the invention is not obvious based on prior knowledge available to the public. ${ }^{36}$ However, it is not always clear whether a repositioned use is inventive in light of the existing science. ${ }^{37}$ Thus, it might be impossible or difficult to obtain a valid patent.

A third challenge for the validity of a new use patent is that sufficient information must be disclosed in the patent application at the date it is filed. The European Patent Office and various contracting states to the European Patent Convention

\footnotetext{
29 See generally European Medicines Agency (2019), Wording of Therapeutic Indication.

${ }^{30}$ European Commission (2007), p. 4. For the purposes of this study, repositioning is limited to instances when the wording of an indication is changed.

31 For a history on these patents, see Bostyn (2016b), pp. 205-209; Fisher (2017), p. 574.

32 Breckenridge and Jacob (2019), p. 2; Cordery and Willis (2017), p. 27; Lietzan (2018), pp. 182-191; Eisenberg (2005), pp. 720-725; Halabi (2018), pp. 24-25; Pushkapom (2018), pp. 50-51.

33 European Patent Convention (1973), Art. 54.

34 Breckenridge and Jacob (2019), p. 2; Eisenberg (2005), p. 724; Roin (2009), pp. 517-531; Pushkapom (2018), pp. 50-51.

35 European Patent Convention (1973), Art. 56.

36 Breckenridge and Jacob (2019), p. 2; Eisenberg (2005), p. 724; Roin (2009), pp. 531-545; Pushkapom (2018), pp. 50-51.

37 Roin (2009), pp. 544-545.
} 
require that patent applications provide evidence showing that the drug could plausibly treat the indication. ${ }^{38}$ This raises two problems. The first is that patent applications with insufficient data will be refused and, if a patent is granted, a competitor could successfully invalidate it. ${ }^{39}$ The second problem is that generating this evidence may take significant time, during which the drug might be disclosed in scientific literature (meaning the patent is no longer novel) or the science advances to the point where the treatment is obvious (meaning the patent no longer involves an inventive step). ${ }^{40}$

The difficulty of enforcing patents has been described as probably the most important topic affecting repositioning. ${ }^{41}$ The issue results from the intersection of the scope of protection for second medical use claims and the way drugs are patented, manufactured, sold, prescribed, and dispensed, but arises only when a generic is marketed for an indication other than the repositioned indication, such as the first known medical use. The difficulty created by the interaction of these facets of the drug industry begins with the way doctors prescribe drugs.

Doctors commonly prescribe drugs by standardised international non-proprietary names (INNs), which the World Health Organisation selects. ${ }^{42}$ Pharmacists then usually dispense drugs relying on INNs without direct knowledge of patients' conditions. ${ }^{43}$ With a generic on the market, pharmacists will have the generic on their shelf as well as the drug protected by a second medical use patent (commonly known as a "branded drug"). This means that when pharmacists receive an INN prescription, they, in principle, have a choice between dispensing the generic or the branded drug.

Labels and packaging information on branded and generic drugs are often different. A branded drug with an MA for a repositioned use will usually describe the repositioned indication (as well as the other indications) in its labels and packaging information, whereas generic drugs typically omit the new use if protected by a patent (or market protection), a practice known as "skinny labelling". ${ }^{44}$ The pharmacist's choice to dispense a generic or branded drug will be informed by many factors (e.g. formulation, convenience of dosage) but, like many choices, cost is often crucial. The mechanisms guiding generic and branded drug prescription vary between countries and can involve several layers of regulation. ${ }^{45}$ Breckenridge and Jacob summarise the situation stating "most countries always

\footnotetext{
38 Case Law of the Boards of Appeal (2019), 7.2 Level of disclosure required for medical use plausibility. Plausibility is not a standalone requirement for a valid patent. Rather, it is a principle that is relevant to various aspects of different jurisdictions' patent law, including inventive step, sufficiency and industrial applicability; for a review, see England (2014), p. 22. Not all Member States have imported the concept of plausibility but do apply similar criteria, see e.g. Ackermann (2020), pp. 4-5.

39 Breckenridge and Jacob (2019), p. 2.

40 Breckenridge and Jacob (2019), p. 2.

41 Breckenridge and Jacob (2019), p. 2.

42 World Health Organisation (1997).

43 Breckenridge and Jacob (2019), p. 2; England (2014), pp. 427-431; Warner-Lambert Co LLC v Generics (UK) Ltd [2019] 3 All ER 95 at [65]-[66].

44 See e.g. Warner-Lambert [2019] 3 All ER 95 at [8].

45 Bostyn (2016a), pp. 158-160.
} 
provide a financial incentive to the pharmacists to dispense a (cheaper) generic medicine when available". 46 Commentators call the scenario of pharmacists dispensing generic drugs for indications that are omitted from the labels as "crosslabel" (or "off-label") use, ${ }^{47}$ and Breckenridge and Jacob argue that the issue is so significant that "if a generic version of a drug is available, developers have little or no opportunity to recoup their investment in the development of the drug for a new indication". 48

The challenges to obtaining and enforcing second medical use patents are not abstract concerns. Appellate courts from across Europe, including from the UK, Germany, Italy, Spain, The Netherlands, Belgium, Switzerland and others, have decided cases, ${ }^{49}$ and the 2018 UK Supreme Court decision Warner-Lambert Co $L L C v$ Generics (UK) Ltd demonstrates the issues starkly. ${ }^{50}$ The decision concerned a second medical use patent for the drug pregabalin. One of the primary claims was addressed to treating neuropathic pain and the other to treating pain in general (the drug was first patented for epilepsy). ${ }^{51}$ The Court invalidated these claims on the grounds of plausibility. ${ }^{52}$ The patent showed pregabalin was effective at treating inflammatory pain in mice, but the Court found the science of pain meant that this finding did not mean the drug could plausibly treat neuropathic pain or pain in general. ${ }^{53}$

Since the patent was found invalid, all the judgments on infringement are obiter. The Court was split on how to evaluate infringement, ${ }^{54}$ but three of the five Lords were of the view that skinny labelling will normally relieve generics of liability for cross-label use. Lord Sumption, with whom Lord Reed agreed, stated that, if the patent was valid, it was not infringed by the generic manufacturers' pregabalin when sold with a skinny label. They stated that the "outward presentation" of the packaging meant it was not intended to be manufactured for the patented purposes. ${ }^{55}$ Lord Mance generally agreed but added a caveat. He stated that skinny labelling would "normal[ly]" absolve a generic company of liability, ${ }^{56}$ but also stated that "there might be some circumstances in which a generic manufacturer could or should be expected to go further, by a notice positively excluding the patent-protected use". 57

\footnotetext{
${ }^{46}$ Breckenridge and Jacob (2019), p. 2; see also Bostyn (2016a), pp. 158-160; Cordery and Willis (2017), p. 26; Liddicoat (2015), p. 174; Lietzan (2018), pp. 183-192; Pushkapom (2018), p. 51.

47 Cordery and Willis (2017), p. 26; Lunze (2014).

48 Breckenridge and Jacob (2019), p. 2.

49 See generally Bühling (2016).

50 Warner-Lambert [2019] 3 All ER 95.

51 Warner-Lambert [2019] 3 All ER 95 at [4]-[5].

52 Warner-Lambert [2019] 3 All ER 95 at [17]-[54]

53 Warner-Lambert [2019] 3 All ER 95 at [50]-[54], [90], [176]-[185], [196].

54 Lords Briggs and Hodge favoured a "subjective intent test", see Warner-Lambert [2019] 3 All ER 95 at [172]-[174], [188].

55 Warner-Lambert [2019] 3 All ER 95 at [84]-[86].

56 Warner-Lambert [2019] 3 All ER 95 at [218].

57 Warner-Lambert [2019] 3 All ER 95 at [213].
} 


\subsection{Study Aims}

Commentators have responded to the arguments that repositioning is underincentivised by suggesting several types of reform. Some suggest changes to regulations and guidelines surrounding prescribing and dispensing practices, with the intention of ensuring only branded drugs are dispensed for repositioned uses. ${ }^{58}$ Others suggest changes to patent law, ${ }^{59}$ the creation of special global funds, ${ }^{60}$ cash rewards, or "tradable voucher" schemes. ${ }^{61}$ Commentators have also raised the idea of lengthening the +1 . Breckenridge and Jacob argue that lengthening the +1 might be sensible as it would compensate a company for its expenditure in clinical trials, even if a patent is unavailable. ${ }^{62}$

Breckenridge and Jacob's argument is plausible, but is it supported by evidence? This study is motivated by that question. Basic capitalist logic suggests that if society increases market protection for a class of products, then companies will be more interested in producing those products because the exclusivity will help yield financial rewards. However, if market protection is too long, the detriments (e.g. non-competitive pricing) will outweigh the gains from spurring production.

The European Commission designed the +1 thinking it found the "right balance" between protection and market competition. ${ }^{63}$ Yet, an EU commissioned report in 2000 (before the +1 was introduced) found "relatively little hard evidence" to support the introduction of a +1 -type exclusivity and none about its duration. ${ }^{64}$ The lack of empirical data is a problem given that the justification for the exclusivity assumes that companies are insufficiently incentivised without it, even though many incentives exist. These incentives include market demand, first-mover advantage, brand power, ${ }^{65}$ established manufacturer facilities, scientific expertise in the drug, patent rights, and market protection (remaining from when the drug was first authorised).

Although a dearth of data exists on the +1 , sufficient time has now passed to examine the effectiveness of the law to achieve the stated goal of incentivising drug repositioning. The EMA began in $1995,{ }^{66}$ providing the first opportunity for companies to obtain EEA-wide MAs, and the +1 came into effect on 20 November 2005. The +1 is only available to drugs with submission dates for primary (not repositioned) MAs after this date. ${ }^{67}$ This means the efficacy of the +1 can be evaluated by comparing the drugs that were submitted for primary MAs before

\footnotetext{
58 Cordery (2013), p. 57; Cordery and Willis (2017), p. 28; Breckenridge and Jacob (2019), p. 2. For the US perspective, see Lietzan (2018), pp. 197-209.

59 Jacob (2018), pp. 6-7.

${ }^{60}$ Cordery and Willis (2017), p. 27.

61 Breckenridge and Jacob (2019), p. 2.

62 Breckenridge and Jacob (2019), p. 2. Breckenridge and Jacob make this argument as a complement to prescription reform.

63 Liikanen (2002).

64 CMS Cameron McKenna and Andersen Consulting (2000), p. 18.

65 O'Connell et al. (2012), p. 54.

66 The European Agency for the Evaluation of Medicine Products (1995).

${ }^{67}$ Regulation 726/04, Arts. 14(11) and 90.
} 
20 November 2005 with those submitted after. However, this study is limited to drugs that received primary MAs up to the end of 2010. Drugs are only counted as repositioned if the repositioning occurred within eight years of the primary MA, and drugs that received MAs in 2011 or later are excluded because the eight-year eligibility period to obtain the +1 had not elapsed before this study began.

This study aims to answer two specific questions. First, whether the +1 increased the proportion of drugs repositioned by MAHs; and second, whether the +1 increased the number of times drugs are repositioned by MAHs, as MAHs often reposition their drugs more than once. The secondary aim is to generate data on repositioned drugs across the lifetime of the EMA. The EU currently has no data on the proportion of MAHs that repositioned their drugs over time, and this information is key to assessing the extent that other factors incentivise repositioning.

\section{Analysis of EMA Drug Authorisations}

\subsection{Refining the Cohort of MAs to Analyse}

An MAH can reposition a drug for which it holds an Art. 8(3) MA and obtain the +1 via one of two procedural routes. The first and most common route is by expanding the extant MA by submitting a type-II variation or an extension application. ${ }^{68} \mathrm{~A}$ key difference between these processes is that extension applications can include other changes to the pharmaceutical form of the drug (e.g. tablet, capsules, IV) and route of administration (e.g. injection, oral administration). ${ }^{69}$

The second route is by submitting a second Art. 8(3) MA. A study that assessed the number of filings by both routes shows that the ratio of times a drug is repositioned via the first route (by amending an extant authorisation) compared to the second route (filing another application under Art. 8(3)) is between 60:1 and $10: 1{ }^{70}$ One reason for the wide range is that in some situations it can be difficult to distinguish between a drug being repositioned by a second application under Art. $8(3)$, and a "new active substance", which does not qualify as repositioning for the purposes of the $+1 .^{71}$ Sometimes two Art. 8(3) MAs appear to be for the same drug because they use the same or similar active ingredient (e.g. salts, polymorphs), which indicates repositioning, but the active ingredients might differ in subtle yet important ways that affect safety or efficacy. If the safety or efficacy is "significantly different" then the EMA classifies the second compound as a "new

\footnotetext{
${ }^{68}$ European Medicines Agency, European Medicines Agency Post-authorisation Procedural Advice for Users of the Centralised Procedure (2021), p. 126.

69 European Medicines Agency, Extensions of Marketing Authorisations: Questions and Answers (n.d.); European Medicines Agency, European Medicines Agency Post-authorisation Procedural Advice for Users of the Centralised Procedure (2021), p. 41.

70 Balogh (2016), pp. 12-13.

71 European Commission (2015), pp. 9-10, 43.
} 
active substance". ${ }^{72}$ The EMA now records whether a drug is a new active substance in all Art. 8(3) MAs, but this was not always the case. ${ }^{73}$ This study analysed repositioning via the first route only for two reasons. First, it is much more common and, second, repositioning is difficult to identify under Art. 8(3) when not labelled by the EMA.

The method to collate all the repositioned drugs consisted of several steps. The EMA maintains a database of all medicines it authorises, ${ }^{74}$ including veterinary drugs and generics. This database was downloaded on 3 July 2019, containing 1,565 products. Only drugs with Art. 8(3) MAs are eligible for the $+1,{ }^{75}$ therefore, only drugs authorised under this or the equivalent antecedent process, Art. 4 of Directive $65 / 65$, were retained in the database for this study. ${ }^{76}$ Various other types of products were removed, ${ }^{77}$ including veterinary medicines, generics, biosimilars, "hybrid medicines", ${ }^{78}$ and combinations of known drugs. ${ }^{79}$ Diagnostics and radiopharmaceutical precursors were also removed because they are not drugs.

This study also removed duplicate drug authorisations because their inclusion may bias the results. For this project, duplicate entries were defined as drugs that had the same: (i) anatomical therapeutic chemical classification code (a system maintained by the World Health Organisation to classify drugs) ${ }^{80}$ (ii) active substance; (iii) medical indication; and (iv) were submitted or authorised within two weeks of each other.

The removed products totalled 823, leaving 742 drugs authorised under Art. 8(3) or Art. 4 of Directive 65/65.

\subsection{Dates and Information on Repositioned Indications}

The EMA database, at download, included the primary MA dates for each drug but not the dates the applications for primary MA were submitted (submission dates). Submission dates are important to this study because they, amongst other criteria,

\footnotetext{
72 European Commission (2015), p. 48.

73 Balogh (2016), pp. 12-13.

74 European Medicines Agency, Download Medicine Data (n.d.); Regulation 2309/1993 laying down Community procedures for the authorisation and supervision of medicinal products for human and veterinary use and establishing a European Agency for the Evaluation of Medicinal Products [1993] OJ L214/1.

75 Regulation 726/2004, Art. 14(1). Note: drugs that must be authorised through the centralised procedure expanded when Regulation 726/2004 replaced Regulation 2309/1993. Regulation 2309/1993, Art. 3(1) (via the Annex), specified that the centralised procedure was mandatory for drugs made by biotechnologies processes only, and Regulation 726/04, Art. 3(1) (via the Annex), added drugs that treat cancer, diabetes, acquired immune deficiency syndrome (AIDS) and diabetes. This list was further expanded on 20 May 2008 to include auto-immune disease and other immune dysfunctions as well as viral diseases. To the authors' knowledge there is no reason to expect that this change in drugs that must be authorised through the centralised procedure should lead to more or less repositioning.

76 Directive 65/65, Art. 4.

77 A similar method was adopted in Langedijk et al. (2016), p. 349.

78 European Medicines Agency, Generic and Hybrid Medicines (n.d.).

79 Directive (2001/83), Art. 10(b).

${ }^{80}$ World Health Organisation (2018).
} 
determine whether a drug is eligible for the +1 (drugs are only eligible for the +1 if the Art. 8(3) MA application was submitted after 20 November 2005). The EMA publishes a European Public Access Report (EPAR) for each drug that it grants or refuses an $\mathrm{MA}^{81}$ and all EPARs now include submission dates for primary MAs. However, submission dates have not always been included, especially for drugs authorised before 2000 .

On 27 occasions a submission date was not recorded in an EPAR, so validation dates were used instead. The EMA validates MA applications after confirming that all the necessary information is included for evaluation and normally occurs in approximately 13 days. ${ }^{82}$ This study obtained the validation dates from the EMA's annual reports. ${ }^{83}$ The use of validation dates instead of the submission dates could incorrectly label a drug as eligible for the +1 . This could occur if the application was submitted before 20 November 2005 and validated after 20 November 2005 . However, none of the validation dates used were after 20 November 2005, which means no drugs were incorrectly labelled as eligible for the +1 . The submission and primary MA dates of the 742 drugs are represented in Fig. $1 .^{84}$

The database downloaded from the EMA contained no specific information about repositioning. Consequently, data on repositioning were collected from the EPARs. ${ }^{85}$ Various details of the repositioned indications were collected, including the new indication, ${ }^{86}$ whether it was authorised, whether the applicant applied for the +1 , and the date the European Commission (on advice from the EMA) ${ }^{87}$ authorised the repositioned indication. The data collection concluded on 20 August 2019.

Figure 1 shows "first repositioning" over time. This term refers to the first time the Commission authorised an expansion of the drug's indication. Figure 1 shows that there has been a general increase in first repositioning over time, meaning the absolute number of drugs repositioned by the MAHs has increased. However, since

\footnotetext{
81 European Medicines Agency, European Public Assessment Reports: Background and Context (n.d.).

82 European Medicines Agency (2017), p. 4.

83 European Medicines Agency, Annual Reports and Work Programmes (n.d.).

84 The EMA was not formally operating until 10 February 1995, yet three EPARs state that drugs were submitted before this date. We expect this occurred because pharmaceutical companies knew the EMA was near operating and wanted to take advantage of the central authorisation process. It also occurred during a time when all the EMA's procedures were still being developed. For simplicity and convenience, these applications were listed in the database as submitted on 10 February 1995.
}

85 EPARs typically contain similar documents, although the labels and contents have changed over time. The first documents examined were summaries of changes to the drug, these were usually titled "procedural steps taken and scientific information after the authorisation", which were found in the section of the EPAR titled "overview of procedural steps taken before and after authorisation". The summary documents were read for references to "variations", "indications", "extensions" and "C.I.6.a", which is the classification used by the EMA for additional indications or modifications to existing indications. The relevant variation assessment reports and scientific discussions were then consulted for the details of the repositioning. If the summary documents were unavailable or only covered a limited time period, then all "assessment reports" and "scientific discussions" outside the summary documents were examined.

${ }^{86}$ Not all type-II variations are extensions of indication; for example, some restricted the indication, see European Medicines Agency (2021), p. 126. It should be noted that on three occasions EMA documents described an extension of indication but did not disclose how the indication expanded.

87 European Medicines Agency, European Commission Decision. 


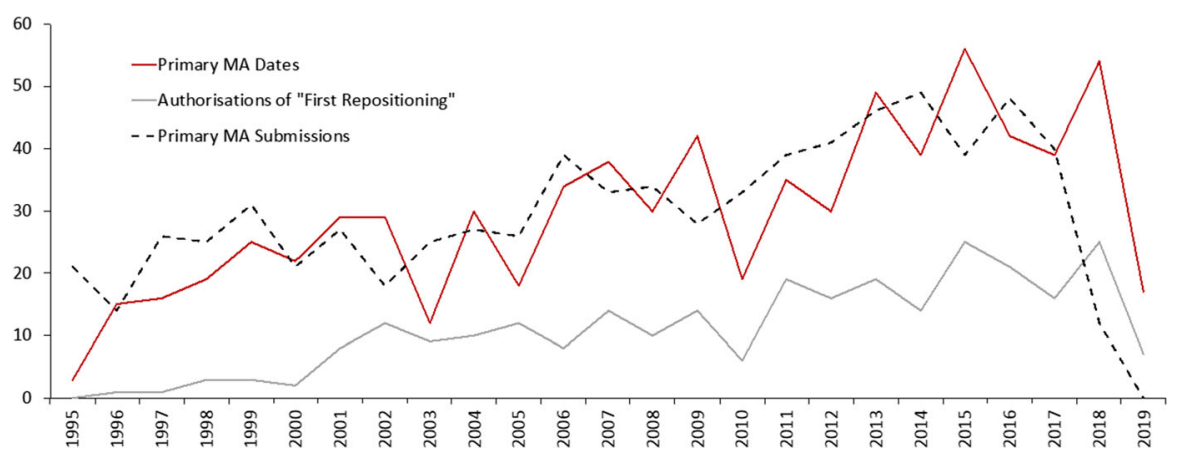

Fig. 1 Graphic representation of: primary MA submissions, primary MA dates and "first repositioning" (the first time a drug is repositioned by the MAH). All categories fluctuate but increase over time. (This figure includes repositioning via deferred PIP data; see below for an explanation)

the number of primary MAs has increased as well, Fig. 1 does not show whether the proportion of drugs repositioned by MAHs or the number of times drugs are repositioned by MAHs has increased.

In 2010, the number of Art. 8(3) applications dropped steeply. This could be due to the global financial crises in 2007 and 2008. That said, some data refute that the crises influenced activity inordinately. For instance, Art. 8(3) submissions and first repositioning activity were relatively high in 2009. Further, 2010 was not the only year to experience marked drops in MAs or submissions: similar drops were observed in 2003 and 2016-17. This suggests that the 2007-2008 crises impacted activity in a similar manner to events in other years. Nevertheless, any conclusions drawn by this study should bear the crisis as well as other events like this in mind.

\subsection{Untangling the Effects of the Paediatric Regulation}

The +1 is not the only EU regulatory law that encourages repositioning. Regulation $1901 / 2006,{ }^{88}$ the "Paediatric Regulation", was passed with the primary goal of increasing the number of drugs authorised to treat children. ${ }^{89}$ The Regulation achieves this goal through Arts. 7 and 8, which oblige organisations to carry out paediatric investigations in certain circumstances. The Regulation rewards the completion of these investigations with a six-month extension of the MAHs' Supplementary Protection Certificates (SPCs). ${ }^{90}$ SPCs extend patent rights to offset the time it takes for MAHs to complete clinical trials and reach market. ${ }^{91}$

\footnotetext{
${ }_{88}$ Regulation 1901/2006 on medicinal products for paediatric use [2004] OJ L378/1.

89 European Commission (2017), p. 5.

90 Regulation (1901/2006), Art. 36(1).

91 Regulation 469/2009 concerning the supplementary protection certificate for medicinal products [2009] OJ L151/1; European Commission, Supplementary Protection Certificates for Pharmaceutical and Plant Protection Products (n.d).
} 
Commencing on 26 July 2008, Art. 7 concerns Art. 8(3) applications, ${ }^{92}$ while Art. 8 commenced on 26 January 2009 and deals with applications for new indications (i.e. applications to reposition a drug). ${ }^{93}$

To meet the requirements of Arts. 7 and 8, the results of a Paediatric Investigation Plan (PIP) are typically required, which usually include paediatric clinical trial data. ${ }^{94}$ However, exceptions exist. In the case of Art. 8 and applications for new indications, the results of a PIP are required only if the drug is protected by an SPC or a patent that qualifies for one, ${ }^{95}$ and for both Arts. 7 and 8, the EMA can grant a waiver, ${ }^{96}$ for example, if the drug treats a disease that does not afflict children. Furthermore, the EMA can grant a deferral, which means the MAH must provide the results of the PIP at a later date. ${ }^{97}$ Deferrals are frequently granted because recruiting children for clinical trials is time-consuming. Without permission to defer, a drug's MA could be delayed with consequent problems for non-paediatric patients. ${ }^{98}$

The Paediatric Regulation is relevant to this study because deferrals raise the possibility that a drug will be repositioned for a paediatric cohort at a later date. This means that, in certain circumstances, the Paediatric Regulation drives repositioning, rather than the +1 .

This study evaluated the impact of Arts. 7 and 8 on repositioning. The effect of Art. 7 was examined by analysing the repositioning of drugs submitted for primary MAs after 26 July 2008. Five drugs were found that were repositioned for a paediatric cohort pursuant to a PIP based on a deferral to a primary MA. The effect of Art. 8 was examined by analysing all repositioning after 26 January 2009. Ten drugs were found that were repositioned for a paediatric cohort pursuant to a PIP based on a deferral to an application for a new indication, and for two of these drugs this occurred twice. These instances of deferral-related repositioning are discussed in the context of other data below.

As mentioned, the Paediatric Regulation not only requires paediatric investigations, but also rewards the completion of the PIP. If the drug is protected by an SPC or a patent that qualifies for an SPC, the MAH is entitled to a six-month SPC extension. However, if an MAH obtains a +1 , then it is precluded from obtaining the six-month SPC extension. ${ }^{99}$ None of the MAHs that repositioned drugs pursuant to a PIP in this study applied for the +1 .

\footnotetext{
92 Regulation (1901/2006), Art. 5(2).

93 Regulation (1901/2006), Art. 5(2).

94 Regulation (1901/2006), Art. 7; European Commission (2017), p. 20.

95 Regulation (1901/2006), Art. 8.

96 Regulation (1901/2006), Arts. 7(b)-(c), 8 and 11.

97 Regulation (1901/2006), Arts. 7(d), 8, 20 and 21.

98 European Commission (2017), pp. 9, 20.

99 Regulation (1901/2006), Art. 36(5).
} 
Table 1 Comparison of the proportion of repositioned drugs by MAHs before and after the +1 came into effect, showing an increase of $0.2 \%$ after the law came into effect

\begin{tabular}{llll}
\hline $\begin{array}{l}\text { Time frames of primary MA } \\
\text { submissions }\end{array}$ & $\begin{array}{l}\text { \# of Drugs } \\
\text { receiving primary } \\
\text { MAs }\end{array}$ & $\begin{array}{l}\text { \# of Drugs repositioned within } \\
\text { eight years of the primary MAs }\end{array}$ & $\begin{array}{l}\% \\
\text { Repositioned }\end{array}$ \\
\hline $\begin{array}{l}\text { Before the }+1 \text { came into effect } \\
\text { (1 Jan } 1995 \text { to } 20 \text { Nov 2005) }\end{array}$ & 256 & $108(108)$ & $42.2(42.2)$ \\
$\begin{array}{l}\text { After the }+1 \text { came into effect } 21 \\
\text { Nov 2005 to } 31 \text { Dec } 2010\end{array}$ & 125 & $53(58)$ & $42.4(46.4)$
\end{tabular}

The bracketed numbers are the values if repositioning via deferred PIP data is included

\section{Data on the Proportion of Repositioned Drugs and the Number of Times Drugs Were Repositioned}

This study aimed to evaluate two ways the +1 might have increased repositioning activity. First, this study investigated whether the +1 increased the proportion of drugs repositioned by MAHs; Table 1 shows these results. Second, this study investigated whether the number of times drugs were repositioned by MAHs increased; Table 3 shows these results. Furthermore, this study tracked the instances that MAHs applied for the +1 in the dataset. The EMA granted 14 applications for the +1 and refused five, while an MAH withdrew another.

The layout of Tables 1,2 and 3 reflect the two time-based criteria to obtain the +1 . All three tables are divided into time frames based on primary MA submission dates. Submission dates are used because one of the criteria for the +1 is that only drugs submitted for an MA after 20 November 2005 are eligible. Tables 1 and 3 use two time frames, "before the +1 came into effect" and "after the +1 came into effect". This means that the 256 drugs that received primary MAs in the first row of Table 1 all had submission dates before 20 November 2005 (even though some were authorised and repositioned after this date). A second criterion for the +1 is that the MAH must reposition the drug within eight years of the primary MA. This criterion was applied to all drugs in this study, not just those with submission dates for primary MAs after 20 November 2005. The application of the eight-year criterion to all drugs in this study enables an assessment of whether the +1 increased repositioning.

Table 1 shows that $42.2 \%$ of drugs (108/256) were repositioned by MAHs before the +1 came into effect, compared with $42.4 \%$ (56/125) after. The bracketed numbers in Table 1 refer to values if drugs repositioned pursuant to a PIP are included. These results nominally indicate that the +1 increased the proportion of repositioned drugs by $0.2 \%$, however, this equates to no "extra" repositioned drugs or effectively the same amount of repositioning. The $0.2 \%$ difference is not 
Table 2 Proportion of repositioned drugs by submission year (excluding repositioned drugs via deferred PIP data), showing a low of $21.4 \%$ in 1996 and a high of $63.0 \%$ in 2004

\begin{tabular}{llcl}
\hline $\begin{array}{l}\text { Year of primary MA } \\
\text { submissions }\end{array}$ & $\begin{array}{l}\text { \# of Drugs receiving } \\
\text { primary MAs }\end{array}$ & $\begin{array}{l}\text { \# of Drugs repositioned within eight } \\
\text { years of the primary MAs }\end{array}$ & $\begin{array}{l}\% \\
\text { Repositioned }\end{array}$ \\
\hline 1995 & 21 & 12 & 57.1 \\
1996 & 14 & 3 & 21.4 \\
1997 & 26 & 9 & 34.6 \\
1998 & 25 & 10 & 40.0 \\
1999 & 31 & 13 & 41.9 \\
2000 & 21 & 6 & 28.6 \\
2001 & 27 & 11 & 40.7 \\
2002 & 18 & 8 & 44.4 \\
2003 & 25 & 13 & 52.0 \\
2004 & 27 & 17 & 63.0 \\
$2005^{*}$ & 21 & 6 & 28.6 \\
\hline $2006 *$ & 44 & 22 & 50.0 \\
2007 & 33 & 13 & 39.4 \\
2008 & 33 & 14 & 42.4 \\
$2009 * *$ & 15 & 4 & 26.7 \\
\hline
\end{tabular}

Drugs submitted for primary MAs in 2006 or later were eligible for the +1 (marked by the single horizontal line)

Table 3 Comparison of the number of times drugs are repositioned before and after the +1 came into effect, showing an average decrease of 0.1 after the law came into effect

\begin{tabular}{llll}
\hline $\begin{array}{l}\text { Time frames of primary } \\
\text { MA submissions }\end{array}$ & $\begin{array}{l}\text { \# of Drugs repositioned } \\
\text { within eight years of the } \\
\text { primary MAs }\end{array}$ & $\begin{array}{l}\text { Total \# of times the drugs were } \\
\text { repositioned within eight years } \\
\text { of the primary MAs }\end{array}$ & $\begin{array}{l}\text { Average \# } \\
\text { each drug is } \\
\text { repositioned }\end{array}$ \\
\hline $\begin{array}{l}\text { Before the }+1 \text { came into } \\
\text { effect (1 Jan } 1995 \text { to }\end{array}$ & 108 & $215(215)$ & $2.0(2.0)$ \\
$\begin{array}{l}20 \text { Nov 2005) } \\
\text { After the + }+1 \text { came into } \\
\text { effect } 21 \text { Nov } 2005 \text { to }\end{array}$ & $53(58)$ & $99(116)$ & $1.9(2.0)$ \\
31 Dec 2010 & & \\
\hline
\end{tabular}

The bracketed numbers are the values if repositioning via deferred PIP data is included

statistically significant, ${ }^{100}$ though it should be noted that the sample size in this study could only show statistical significance if a $16.2 \%$ increase was observed,

\footnotetext{
${ }^{100}$ McDonald (2014). Fisher's exact test shows that the differences in proportions in Table 1 are not statistically different $(p>0.10)$. The $p$ value is 1.00 when repositioning via deferred PIP data is excluded, and 0.62 when repositioning via deferred PIP data is included. The statistical tests were performed using an online calculator: "Easy Fisher Exact Test Calculator" (n.d.), https://www.socscistatistics.com/tests/ fisher/default2.aspx (accessed 10 December 2020).
} 
which equates to 73 of 125 drugs in the "after" cohort being repositioned. Thus, statistical tests offer limited insight into this analysis.

Table 2 offers finer-grained detail than Table 1 by separating the data into individual years. That said, Table 2 also contains two minor exceptions to this separation. First, four drugs had submission dates in 2005 after 20 November. Table 2 groups these drugs with the drugs submitted in 2006; otherwise the entry for 2005 would include drugs that were both eligible and ineligible for the +1 . Second, two drugs in this study were submitted for primary MAs in 2010 and then authorised in the same year. This occurred because the EMA takes time to authorise drugs, and most drugs submitted in 2010 were authorised in 2011 (as mentioned, drugs authorised in 2011 or later were excluded from this study because the eight-year period for MAHs to obtain the +1 had not elapsed before this study began). Table 2 groups these two drugs with the drugs submitted for primary authorisations in 2009 , otherwise the entry for 2010 would only have two drugs, and this would inaccurately represent repositioning activity. Reminders of these two exceptions are represented in Table 2 with asterisks (one for the first exception and two for the second). These exceptions make it easier to analyse whether the +1 increased the proportion of drugs repositioned by MAHs; the drugs submitted for primary MAs before the horizontal line (1995-2005) were not eligible for the +1 , but the drugs after the horizontal line (2006-2009) were.

One insight from Table 2 can be obtained by comparing the four years immediately before the +1 came into effect with the four years after. This assessment is useful because the comparison is between similar eras of scientific understanding. From 2002 to 2005, 91 drugs were authorised and 44 (48.4\%) of them were repositioned. The four years afterwards are already calculated in Table 1 (42.4\%). This comparison indicates that after the +1 came into effect, the proportion of repositioned drugs decreased by $6.0 \%$ (a difference of approximately seven drugs). If drugs repositioned via deferred PIPs are included in this analysis $(46.4 \%)$, then there was still a decrease of $2 \%$ (approximately two drugs) in the four years after the +1 came into effect.

The decrease of $6.0 \%$ could be linked to the difficulties obtaining patents described in the Background; but no data in this study support that conclusion. Data that would indicate difficulties obtaining patents include sustained periods of decreasing repositioning, which is not evidenced in the data. An alternative explanation is that the four years before the +1 came into effect witnessed a shortterm increase in repositioning and that the years afterwards reverted to the mean. This explanation is more likely as it aligns with the data and with a 2004 commentary that described a "boom" in repositioning. ${ }^{101}$

A question remains about whether drugs repositiond via deferred PIPs would have occurred if the Paediatric Regulation did not exist and, therefore, should be counted with all the other repositioning in the "after" cohort. The EMA's 10-year review of the Paediatric Regulation shows that the Regulation has significantly

$\overline{101}$ Ashburn and Thor (2004), p. 682. 
increased the number of MAs with paediatric indications and the number of type-II variations for paedatric cohorts. ${ }^{102}$ These increases suggest that much of the repositioning can be attributed to the Regulation, but exactly how much remains uncertain. None of the repositioning via deferred PIPs in this study applied for the +1 , which indicates that the +1 did not drive the paediatric repositioning. On balance, then, excluding this repositioning via deferred PIP data seems sensible. However, even if all five extra drugs repositioned by deferred PIP data were included in the "after" cohort, it would have been challenging to conclude that the +1 increased repositioning for three reasons. First, repositioning in the four years before the +1 came into effect would still have been higher. Second, the result would not be statistically significant; and third, which is related to the second, the extra five drugs could be attributed to year-to-year variation in repositioning, which ranges from $21.4 \%(3 / 14)$ to $63.0 \%(17 / 27)$.

This study is limited by the sample size of drugs that received primary MAs. One response to the size of the dataset is to conduct a follow-on study in another five to 10 years, which would likely double or triple the number of drugs that received primary MAs in the "after" cohort. Larger datasets typically provide more precision, and such datasets might even permit researchers to look for statistical differences in the repositioning of different classes of drugs (e.g. orphan drugs and biologics). However, a problem with incorporating data from later years is that scientific and medical environments rapidly change. These changes mean that any comparisons would be between years with increasingly different scientific and regulatory environments. ${ }^{103}$

This paper now turns to whether the +1 increased the number of times drugs were repositioned by the MAHs. As mentioned, drugs are often repositioned more than once, but the +1 can only be obtained once. Table 3 follows the same layout as Tables 1 and 2, orientated around submission dates of primary MA applications. Table 3 shows that if a drug was repositioned then, on average, it was repositioned 2.0 times before +1 came into effect. Table 3 also shows that this number decreased to 1.9 in the "after" cohort. The numbers in Table 3 have been rounded for convenience, and the 0.1 difference equates to a difference of seven fewer times that drugs were repositioned. This result is not statistically significant, ${ }^{104}$ but it should be noted that the sample size in this study could only show statistical significance if the "after" average fell to approximately 1.4. Thus, statistical tests offer limited insight into this analysis too.

The decrease in Table 3 could be linked to the +1 , if the law encouraged MAHs to reposition their drug once and not pursue additional repositioning. However, the proportion of drugs in the "before" cohort that were repositioned once is $52.7 \%$ (57/ 108) compared to the $54.7 \%(30 / 53)$ in the "after" cohort, a difference that is not

\footnotetext{
102 European Medicines Agency (2016), pp. 12-13.

103 See e.g. Feldman (2018), pp. 617-637; Breckenridge (2018), p. 4.

104 McDonald (2015). The Wilcoxon signed-rank test shows that the differences in proportions in Table 3 are not statistically different $(p>0.10)$. The $p$ value is 0.96 when repositioning via deferred PIP data is excluded, and 0.73 when repositioning via deferred PIP data is included. The statistical tests were performed using an online calculator: "Mann-Whitney U Test Calculator" (n.d.), https://www. socscistatistics.com/tests/mannwhitney/default2.aspx (accessed 10 December 2020).
} 
large enough to explain the decrease. Instead, a close look at the number of times certain drugs were authorised suggests a simpler explanation.

The drugs Remicade and Humira were repositioned nine times each, and the drugs Avastin and Glivec were repositioned eight times each. All four were submitted for primary authorisation before 20 November 2005, meaning they were not eligible for the +1 . In comparison, no drugs submitted after 20 November 2005 were repositioned six times or more. If two or three drugs submitted after 20 November 2005 were repositioned eight or nine times, then these numbers would look similar. Consequently, the 0.1 difference observed in Table 3 can be attributed to sample size and the variation in repositioning; that is, if the "after" sample included more drugs, then these averages would probably be closer, as a larger number of drugs would mean there is a greater chance one or two would be repositioned eight or nine times.

\section{Policy Implications}

\subsection{Do the Results Indicate the +1 Increased Repositioning?}

The short answer to this question is "no". To recap, Table 1 effectively shows the same proportion of repositioned drugs before and after the +1 came into effect. The results on the number of times drugs are repositioned tell a similar story. Table 3 shows that if a drug was repositioned, then the average number of times it was repositioned decreased from 2.0 to 1.9 , which is a difference of about seven times drugs were repositioned. This decrease can be explained by drugs in the data that were repositioned six times or more before the +1 came into effect and that no drugs have been repositioned six or more times after. Thus, this difference is likely due to year-to-year variation.

The conclusion that the +1 did not increase the proportion of drugs that were repositioned by MAHs or the number of times drugs were repositioned by MAHs stands even if drugs repositioned based on PIP-deferred data are included in the analysis. (Initially, these drugs were excluded because their existence is arguably owed more to the effect of the Paediatric Regulation than the +1 .) The proportion of repositioned drugs including PIP-based repositioning was $46.4 \%$, which is $2 \%$ lower than the proportion in the four years before the +1 came into effect. And the average number of times drugs were repositioned including PIP-based repositioning was 2.0; which is no change from the average before the +1 came into effect.

A further point to consider is whether the +1 averted a decrease in repositioning activity. In this case, one could argue that the +1 increased repositioning, although the amount of repositioning seems unchanged. As noted, MAHs made 20 applications for the +1 (14 that were successful and six that were not). Perhaps this repositioning would not have occurred if the +1 did not exist? This study does not rule this possibility out; however, the data in this study do not support this interpretation. For instance, Table 2 does not show any sustained decrease in the proportion of repositioned drugs before the +1 came into effect, with a surge after 
the +1 was available. Thus, there are no data in this study to conclude the +1 averted a decrease in repositioning.

If it is correct that the +1 did not increase repositioning, then this outcome likely has significant implications for drug prices. The failure of the +1 to increase repositioning means that most, if not all, of the repositioning observed in the study would have occurred if the +1 did not exist. Consequently, the 14 MAHs that received an additional year of market exclusivity likely cost EEA governments and patients millions of euros in higher prices.

\subsection{Reasons the +1 Had No Effect}

Four reasons potentially explain why the +1 had no impact on repositioning activity. The first reason relates to how the +1 fits alongside patents in IP strategies. The +1 might be valuable in some situations, for example, where the MAH lacks patent protection. However, in many other scenarios, the +1 will be eclipsed by a patent or other rights. For example, MAHs often own a patent protecting the drug compound, which does not suffer the same problems as second medical use patents, ${ }^{105}$ and which has a lifespan of 20 years from the date of filing. ${ }^{106}$ This means that 11 years of market protection from the primary MA may be redundant because the 20-year patent term is longer. In addition, MAHs often obtain other complementary forms of IP. For instance, many MAHs extend their patent protection by up to five years with an SPC. ${ }^{107}$ MAHs can also obtain secondary patents, for example, for second medical uses, improvements to the drug (such as on mechanisms of delivery or refinements to the molecule), or use of the drug with medical devices (e.g. diagnostics). ${ }^{108}$ Thus, although the +1 may be useful in some circumstances, in many other situations it is likely redundant.

The second reason is that society might already be seeing high rates of repositioning by MAHs and expecting more is akin to hoping for a bottomless well. The last four years of data in this study (2005-2009) show that $42.4 \%$ of drugs, or over four in ten drugs, were repositioned. How much more repositioning by MAHs can plausibly be expected? The issue here is that the +1 incentive may be futile.

The third reason is that the eligibility rules for the +1 might be problematic. For instance, the rule that repositioning must occur within eight years of marketing authorisation. The problem is that many indications emerge only serendipitously after years of research and clinical use, ${ }^{109}$ and assembling the requisite data to submit to the EMA takes even longer. This might mean the MAHs cannot meet the eight-year rule, curbing the effect of the +1 . If this is the reason, the +1 incentive is arguably inapt.

Another way in which the eligibility rules for the +1 might be inapt is the requirement that the new indication provide significant clinical benefit compared

\footnotetext{
$\overline{105}$ Kapczynski et al. (2012), pp. 4, 6.

106 European Patent Convention (1973), Art. 63(1).

107 Regulation 469/2009, Art. 13(2).

108 Beall and Kesselheim (2018), p. 142.

109 Polamreddy and Gattu (2018), p. 789.
} 
with existing therapies. Arguably, this condition is too demanding and dissuades MAHs from pursuing the +1 . However, in this study, $73.6 \%$ (14/19) of the applications for the +1 passed the threshold (the one remaining application was withdrawn before it was evaluated because the MAH obtained the +1 for the drug via other repositioning). This relatively high success rate suggests that the "significant clinical benefit" threshold is not the reason for the +1 having limited impact on repositioning activity.

The fourth reason concerns the value of the +1 . Arguably, the extra year is insufficient. Even in circumstances where the +1 offers useful protection, the financial value of a single extra year might not outweigh the research costs. Although the +1 provides market protection for both the old and the new indications, ${ }^{110}$ the research costs include both actual and opportunity costs, and MAHs might decide that other projects in their pipelines present more lucrative opportunities.

A further issue is that cross-label use of a generic might reduce financial returns. However, cross-label use is not a given, as several strategies can limit or avoid it; for example, MAHs can sometimes change the dose, formulation or route of administration of the drug. ${ }^{111}$ Moreover, if an MA is for a new active substance, then the MAH is unlikely to encounter any cross-label use until the 11 years of market protection lapses; this occurs because market protection stops generics from being marketed. In 2019, 84.2\% of Art. 8(3) MAs were for new active substances. ${ }^{112}$ Consequently, whether the value of the +1 is insufficient is a complex issue that warrants considerably more study.

\subsection{The Future of the +1}

This study indicates that the +1 did not increase the proportion of drugs repositioned by MAHs nor the number of times drugs were repositioned by MAHs. But, as discussed in the previous section, there are at least four possible reasons why the +1 failed to have these effects. The +1 might be redundant, futile, inapt or insufficient. Without knowing more about these reasons, one cannot conclude whether the +1 should be amended or even repealed.

Useful information could be obtained through comparative research with US legislation. US law provides a period of exclusivity for new medical indications, however, the scope and duration of the protection differ from the European approach. For example, the US provides three years of protection, and the protection takes the form of preventing approvals for the new indication only (not market protection for all the MAH's indications). ${ }^{113}$ Additionally, US law allows applications to be made by any party at any time after the primary MA (there is

\footnotetext{
$\overline{110}$ Directive (2001/83), Art. 6(1); Riberio (2018), p. 6; European Commission (2015), pp. 9-10, 43.

${ }^{111}$ Phelps (2012), pp. 82-83; Frail (2012), pp. 396-399; Persidis and Stark (2012), pp. 436-437. See also Apotex Pty Ltd v AstraZeneca AB [No 4] (2013) 100 I.P.R. 285 at 411; for a review of this litigation, see Liddicoat (2015), pp. 175-6.

112 European Medicines Agency (2020).

11321 U.S.C. $\S \S 355(\mathrm{~b})(2), 355(\mathrm{c})(3)(\mathrm{E})((\mathrm{iii})-(\mathrm{iv}), 355(\mathrm{j})(5)(\mathrm{F})(\mathrm{iii})-(\mathrm{iv})$.
} 
no eight-year time limit), and there is no requirement to prove significant clinical benefit. The only requirement is that the application includes "essential" new clinical investigations that support the authorisation of the new indication. ${ }^{114}$ Research similar to this study could investigate whether the US approach has been effective. If so, it might suggest that the +1 should be amended so that it is more effective.

Another line of research would be to interview or survey scientific researchers in industry and academia. Respondents could be asked whether they discontinued a repositioning project and, if so, why. Was it because there was insufficient market exclusivity, or was it due to other factors such as too much uncertainty about the science or other more pressing research goals?

If evidence emerges that the +1 failed to incentivise repositioning because it is too short, several lines of research should be pursued before it is lengthened. Research would be needed to investigate the duration needed to spur more repositioning. Research should also calculate the financial cost of additional exclusivity. Exclusivity affects competitive pricing, and so the costs must not outweigh the added utility of the new indication. In addition, research could provide a more fine-grained analysis of whether certain classes of repositioning should be excluded from obtaining the +1 . For example, a close inspection of repositioning before the +1 came into effect might reveal classes of repositioning that will reliably occur without offering extra market protection.

If further research shows no reason to extend the +1 , then we should consider repealing the incentive. This study indicates that the +1 not only failed to increase repositioning, but that it imposes a cost on society for no benefit, or, in other words, a deadweight loss. To recap, this study found 14 instances where MAHs successfully obtained the +1 . These MAHs received an additional year of market exclusivity for all the authorised uses of their drug (the old as well as the new). Therefore, the +1 likely prevented competitive pricing for an extra year, meaning governments and patients had to pay higher prices. Although this study indicates that the +1 failed to increase repositioning, the results do not rule out the possibility that the +1 averted a decrease in activity. Additional research could confirm whether the MAHs that received the +1 are deadweight losses. If the +1 has only created deadweight losses, it should be repealed. Alternatively, if this research shows that it is a useful incentive in some situations but generally redundant or futile, then reform might be required. However, this reform would depend on exactly what the research shows.

\section{Conclusion}

This study aimed to evaluate the effectiveness of the +1 by assembling and analysing all the relevant instances of repositioning before and after the exclusivity came into effect. It also sought to capture important ancillary data on drugs repositioned by MAHs since the establishment of the EMA. The results show that

$\overline{114} 21$ U.S.C. $\S \S 355(\mathrm{~b})(2), 355(\mathrm{c})(3)(\mathrm{E})((\mathrm{iii})-(\mathrm{iv}), 355(\mathrm{j})(5)(\mathrm{F})(\mathrm{iii})-(\mathrm{iv})$. 
there was a substantial level of repositioning activity before the +1 came into effect; notably, $42.2 \%$ of MAHs repositioned their drugs. The results show that the proportion of MAHs that repositioned their drugs after the +1 did not increase. The results also show that the average number of times drugs were repositioned by MAHs decreased, but that this was probably due to random variation in repositioning activity. Consequently, this study concludes that the +1 failed to increase repositioning.

Four reasons potentially explain why the +1 failed to increase repositioning: (i) it is redundant due to other IP; (ii) it is futile because MAHs are already pursuing all promising repositioning projects; (iii) it is in inapt due to its eligibility criteria; and (iv) it is insufficient because one extra year of market protection may not outweigh the costs of the additional research.

Three reform options are to lengthen the +1 , repeal it or keep it in its current state. Commentators have suggested lengthening the +1 to increase the incentive for repositioning. This study indicates that this is not advisable unless further evidence emerges. The +1 may have failed to increase repositioning because a single extra year of exclusivity was insufficient. It is also possible that the +1 averted a decrease in repositioning, and that the +1 is now needed to sustain the current levels of repositioning. Repealing the +1 is a plausible option, but research should first examine the +1 's role in sustaining levels of repositioning and investigate whether the MAHs that obtained the +1 are deadweight losses. Consequently, this study suggests we should keep the +1 in its current state for the moment.

Only rarely do individual studies guide policy reform exactly, and this study is no exception. Nevertheless, this study takes the first step towards a comprehensive evidence-based policy for the +1 .

Acknowledgements The authors appreciate all those who aided this study. In particular, we would like to thank Lionel Bently, Christopher Stothers, Henning Grosse Ruse-Khan, James Parish, Matthew Jordan, Timo Minssen, Sven Bostyn, Jonathan Darrow and Rochelle Dreyfuss. We also thank Richard Samworth at the Statistics Clinic, University of Cambridge for statistical advice.

Funding This work was supported, in part, by a Novo Nordisk Foundation grant for a scientifically independent Collaborative Research Programme in Biomedical Innovation Law (Grant Agreement Number NNF17SA0027784).

\section{Declarations}

Conflict of interest The authors have no conflicts of interest.

Availability of data The data are available from the corresponding author on request.

Open Access This article is licensed under a Creative Commons Attribution 4.0 International License, which permits use, sharing, adaptation, distribution and reproduction in any medium or format, as long as you give appropriate credit to the original author(s) and the source, provide a link to the Creative Commons licence, and indicate if changes were made. The images or other third party material in this article are included in the article's Creative Commons licence, unless indicated otherwise in a credit line to the material. If material is not included in the article's Creative Commons licence and your intended use is not permitted by statutory regulation or exceeds the permitted use, you will need to obtain permission directly from the copyright holder. To view a copy of this licence, visit http:// creativecommons.org/licenses/by/4.0/. 


\section{References}

Ackermann M (2020) No need for "plausibility" in German patent law. GRUR Int 70(1):3-10

Allergan Inc et al (2011) Brief of amici curia Allergan Inc, Shire Pharmaceuticals Inc, Medicis Pharmaceutical Corp and Somaxon Corp in support of the respondents. Caraco Pharmaceutical Laboratories Ltd v Novo Nordisk A/S, 566 US 399 (2012)

Ashburn TT, Thor KB (2004) Drug repositioning: identifying and developing new uses for existing drugs. Nat Rev Drug Discov 3:673-683

Balogh S (2016) Extensions of indication in the European Union-a regulatory overview. Master's thesis, Bonn, pp i-112. https://dgra.de/media/pdf/studium/masterthesis/master_balogh_s.pdf. Accessed 10 Dec 2020

Beall RF, Kesselheim AS (2018) Tertiary patenting on drug-device combination products in the United States. Nat Biotechnol 36(2):142-145

Berndt ER, Aitken ML (2011) Brand loyalty, generic entry and price competition in pharmaceuticals in the quarter century after the 1984 Waxman-Hatch legislation. Int J Econ Bus 18:177-201

Bostyn SJR (2016) Personalised medicine, medical indication patents and patent infringement: emergency treatment required. Intell Prop Q 2:151-201

Bostyn SJR (2016) Medical treatment methods, medical indication claims and patentability: a quest into the rationale of the exclusion and patentability in the context of the future of personalised medicine. Intell Prop Q 3:203-230

Breckenridge A (2018) Clinical innovation: fair and effective incentives for new uses of established drugs (8 February 2018, Georgetown University, Washington, D.C., United States). https://www.ucl.ac.uk/ laws/sites/laws/files/ucl_georgetown_clinical-innovation-conference_transcript_08feb18_am.pdf. Accessed 10 Dec 2020

Breckenridge A, Jacob R (2019) Overcoming the legal and regulatory barriers to drug repurposing. Nat Rev Drug Discov 18:1-2

Bühling J (ed) (2016) Patent protection for second medical uses, 1st edn. Kluwer Law International, Alphen aan den Rijn

Case Law of the Boards of Appeal (2019) 9th edn. https://www.epo.org/law-practice/legal-texts/html/ caselaw/2019/e/index.htm. Accessed 17 Feb 2021

CMS Cameron McKenna, Andersen Consulting (2000) Evaluation of the operation of the Community procedures for the authorisation of medicinal products. EC commissioned report, pp 1-302

Cordery B (2013) Use of medicines for carved out indications in Europe-time for a change in approach? J Commer Biotechnol 19:55-58

Cordery B, Willis S (2017) Second medical use issues-progress made and the road ahead. CIPA J 46(4):24-28

DiMasi JA, Grabowski HG, Hansen RW (2016) Innovation in the pharmaceutical industry: new estimates of R\&D costs. J Health Econ 47:20-33

Eisenberg RS (2005) The problem of new uses. Yale J Health Policy Law Ethics 5:717-739

England P (2014) Patents and plausibility. J Intell Proper Law Pract 9:22-30

European Agency for the Evaluation of Medicine Products (1995) First general report on the activities of the European Agency for the Evaluation of Medicinal Products. https:/www.ema.europa.eu/en/ documents/annual-report/annual-report-european-agency-evaluation-medicinal-products-1995_en. pdf. Accessed 10 Dec 2020

European Commission (2006) Volume 2B Medicinal products for human use. Presentation and format of the dossier (June 2006). https://ec.europa.eu/health/sites/health/files/files/eudralex/vol-2/b/update_ 200805/ctd_05-2008_en.pdf. Accessed 10 Dec 2020

European Commission (2007) Guidance on elements required to support the significant clinical benefit in comparison with existing therapies of a new therapeutic indication in order to benefit from an extended (11-year) marketing protection period (November 2007). https:/ec.europa.eu/health/sites/ health/files/files/eudralex/vol-2/c/guideline_14-11-2007_en.pdf. Accessed 17 Feb 2020

European Commission (2015) Volume 2A procedures for marketing authorisation. Chapter 1 Marketing authorisation (July 2015, Revision No. 5). https://ec.europa.eu/health//sites/health/files/files/ eudralex/vol-2/a/vol2a_chap1_201507.pdf. Accessed 10 Dec 2020

European Commission (2017) State of paediatric medicines in the EU: 10 years of EU paediatric regulation. https:/ec.europa.eu/health/sites/health/files/files/paediatrics/docs/2017_childrensmedi cines_report_en.pdf. Accessed 10 Dec 2020 
European Commission (n.d.) Supplementary protection certificates for pharmaceutical and plant protection products. https://ec.europa.eu/growth/industry/intellectual-property/patents/supplemen tary-protection-certificates_en. Accessed 10 Dec 2020

European Medicines Agency (2016) 10-year report to the European Commission (15 August 2017). https://ec.europa.eu/health/sites/health/files/files/paediatrics/2016_pc_report_2017/ema_10_year_ report_for_consultation.pdf. Accessed 24 Feb 2021

European Medicines Agency (2017) Initial (full) marketing authorisation application assessment timetables (31 October 2017). https://www.ema.europa.eu/en/documents/other/timetable-initial-fullmarketing-authorisation-application_en.pdf. Accessed 10 Dec 2020

European Medicines Agency (2019) Wording of therapeutic indication. https://www.ema.europa.eu/en/ documents/regulatory-procedural-guideline/wording-therapeutic-indication-guide-assessorscentralised-applications_en.pdf. Accessed 10 Dec 2020

European Medicines Agency (2020) Annex 10-2019 annual report of the European Medicines Agency - CHMP opinions on initial evaluations and extensions of therapeutic indication (15 June 2020). https://www.ema.europa.eu/documents/annual-report/annex-10-2019-annual-report-europe an-medicines-agency-chmp-opinions-initial-evaluations-extensions_en.xlsx. Accessed 10 Dec 2020

European Medicines Agency (2021) European Medicines Agency post-authorisation procedural advice for users of the centralised procedure (11 January 2021). https://www.ema.europa.eu/en/documents/ regulatory-procedural-guideline/european-medicines-agency-post-authorisation-procedural-adviceusers-centralised-procedure_en.pdf. Accessed 14 Jan 2021

European Medicines Agency (n.d.) Annual reports and work programmes. https://www.ema.europa.eu/ en/about-us/annual-reports-work-programmes. Accessed 10 Dec 2020

European Medicines Agency (n.d.) Download medicine data. https://www.ema.europa.eu/en/medicines/ download-medicine-data. Accessed 10 Dec 2020

European Medicines Agency (n.d.) European Commission decision. https://www.ema.europa.eu/en/ glossary/european-commission-decision. Accessed 10 Dec 2020

European Medicines Agency (n.d.) European public assessment reports: background and context. https:// www.ema.europa.eu/en/medicines/what-we-publish-when/european-public-assessment-reportsbackground-context. Accessed 14 Jan 2021

European Medicines Agency (n.d.) Extensions of marketing authorisations: questions and answers. https://www.ema.europa.eu/en/human-regulatory/post-authorisation/variations/extensionsmarketing-authorisations-questions-answers. Accessed 14 Jan 2021

European Medicines Agency (n.d.) Generic and hybrid applications. https://www.ema.europa.eu/en/ human-regulatory/marketing-authorisation/generic-medicines/generic-hybrid-applications. Accessed 10 Dec 2020

European Medicines Agency (n.d.) Generic and hybrid medicines. https://www.ema.europa.eu/en/humanregulatory/marketing-authorisation/generic-hybrid-medicines. Accessed 14 Jan 2021

Feldman R (2016) Regulatory property: the new IP. Columbia J Law Arts 40:53-103

Feldman R (2018) May your drug price be evergreen. J Law Biosci 5:590-647

Fisher M (2017) Second medical indications and the Swiss-form claim: taming Frankenstein's monster: part 1-solving one problem creates another. Eur Intell Proper Rev 39(9):574-581

Frail DE (2012) Drug repositioning by nonprofit foundations. In: Barratt MJ, Frail DE (eds) Drug repositioning, 1st edn. Wiley, Hoboken, pp 396-432

Grabowski HG, Moe JL (2008) Impact of economic, regulatory and patent policies on innovation in cancer chemoprevention. Cancer Prev Res 1:84-90

Halabi SF (2018) The drug repurposing ecosystem: intellectual property incentives, market exclusivity, and the future of "new" medicines. Yale J Law Technol 20:1-73

Horgan J (2018) Clinical innovation: fair and effective incentives for new uses of established drugs (9 February 2018, Georgetown University, Washington, D.C., United States). https://www.ucl.ac.uk/ laws/sites/laws/files/ucl_georgetown_clinical-innovation-conference_transcript_09feb18_pm.pdf. Accessed 10 Dec 2020

Jacob R (2018) Clinical innovation: fair and effective incentives for new uses of established drugs (9 February 2018, Georgetown University, Washington, D.C., United States). https://www.ucl.ac.uk/ laws/sites/laws/files/ucl_georgetown_clinical-innovation-conference_transcript_09feb18_pm.pdf. Accessed 10 Dec 2020

Kapczynski A et al (2012) Polymorphs and products and salts (oh my!): an empirical analysis of "secondary" pharmaceutical patents. Plos One 7(12):e49470 
Langedijk $\mathbf{J}$ et al (2015) Drug repositioning and repurposing: terminology and definitions in literature. Drug Discov Today 20(8):1027-1034

Langedijk $\mathbf{J}$ et al (2016) Extensions of indication throughout the drug product lifecycle: a quantitative analysis. Drug Discov Today 21:348-355

Liddicoat J (2015) Reluctance realised? emerging problems with s 117(2)(b) of the Patents Act 1990 (Cth). Monash Univ Law Rev 41(1):163-191

Lietzan E (2018) Paper promises for drug innovation. George Mason Law Rev 26:168-214

Lietzan E (2019) The evergreening metaphor in intellectual property scholarship. Akron Law Rev 53:805-871

Liikanen E (2002) European Parliament debates (22 October 2002, Strasbourg). http://www.europarl. europa.eu/sides/getDoc.do?pubRef=-//EP//TEXT+CRE+20021022+ITEM$001+\mathrm{DOC}+\mathrm{XML}+\mathrm{V} 0 / / \mathrm{EN} \&$ language $=\mathrm{EN}$. Accessed 10 Dec 2020

Lunze A (2014) Infringement of second medical use claims in Germany (July 2014). https://unitedkingdom.taylorwessing.com/synapse/ti_infringe2ndmed_ger.html. Accessed 10 Dec 2020

Manley MI, Amos L (2015) Procedures for obtaining a marketing authorisation and legal bases for application. In: Manley MI, Vickers M (eds) Navigating European pharmaceutical law, 1st edn. Oxford University Press, Oxford, pp 79-110

Manley MI, Strachan G (2015) Regulatory data protection. In: Manley MI, Vickers M (eds) Navigating European pharmaceutical law, 1st edn. Oxford University Press, Oxford, pp 255-276

Manley MI, Vickers M (2015) Maximisation of regulatory IP rights. In: Manley MI, Vickers M (eds) Navigating European pharmaceutical law, 1st edn. Oxford University Press, Oxford, pp 301-317

McDonald JH (2014) Fisher's exact test of independence (20 July 2014). http://www.biostathandbook. com/fishers.html. Accessed 10 Dec 2020

McDonald JH (2015) Wilcoxon signed-rank test. http://www.biostathandbook.com/wilcoxonsignedrank. html. Accessed 10 Dec 2020

Nayroles G (2017) Unlocking the potential of established products: toward new incentives rewarding innovation in Europe. J Market Access Health Policy 5:1-15

Nosengo N (2016) New tricks for old drugs. Nature 534:314-316

O'Connell D et al (2012) Clinical and operation considerations in repositioning marketed drugs and drug candidates. In: Barratt MJ, Frail DE (eds) Drug repositioning, 1st edn. Wiley, Hoboken, pp 53-64

Oprea TI, Mestres J (2012) Drug repurposing: far beyond new targets for old drugs. AAPS J 14:759-763

Persidis A, Stark ET (2012) Business development strategies in the repositioning industry. In: Barratt MJ, Frail DE (eds) Drug repositioning, 1st edn. Wiley, Hoboken, pp 436-437

Phelps K (2012) Regulatory considerations and strategies for drug repositioning. In: Barratt MJ, Frail DE (eds) Drug repositioning. Wiley, Hoboken, pp 65-88

Prasad V, Mailankody S (2017) Research and Development spending to bring a single cancer drug to market and revenues after approval. JAMA Internal Med 177(11):1569-1575

Polamreddy P, Gattu N (2018) The drug repurposing landscape from 2012 to 2017: evolution, challenges, and possible solutions. Drug Discov Today 24(3):789-795

Pushkapom S (2018) Drug repurposing: progress, challenges and recommendations. Nat Rev Drug Discov 18:41-58

Riberio S (2018) Data exclusivity, market protection, orphan and paediatric rewards. https://www.ema. europa.eu/en/documents/presentation/presentation-data-exclusivity-market-protection-orphanpaediatric-rewards-s-ribeiro_en.pdf. Accessed 10 Dec 2020

Roin BN (2009) Unpatentable drugs and the standards of patentability. Texas Law 87(3):503-570

Sahoo A (2007) Indication expansion: opportunities for successful lifecycle management. Business Insights Ltd, London

United States Food \& Drug Administration (2018) Generic drug facts. www.fda.gov/Drugs/ ResourcesForYou/Consumers/BuyingUsingMedicineSafely/UnderstandingGenericDrugs/ ucm167991.htm. Accessed 10 Dec 2020

World Health Organisation (1997) Guidance on INN. https://www.who.int/medicines/services/inn/ innquidance/en/. Accessed 10 Dec 2020

World Health Organisation (2018) Structure and principles. https://www.whocc.no/atc/structure_and_ principles/. Accessed 10 Dec 2020 


\section{Cases}

Apotex Pty Ltd v AstraZeneca AB [No 4] (2013) 100 I.P.R. 285

R. $v$ The Medicines Control Agency (C-368/96) EU:C:1998:583; [1998] E.C.R. I-7967; [1999] 2 C.M.LR

Warner-Lambert Co LLC v Generics (UK) Ltd [2019] 3 All ER 95

\section{Legislation}

\section{U.S.C. $§ 355$}

European Patent Convention 1973

Directive 65/65/EEC on the approximation of provisions laid down by law, regulation or administrative action relating to proprietary medicinal products [1987] OJ L15/36

Directive 87/21/EEC amending Directive 65/65/EEC on the approximation of provisions laid down by law, regulation or administrative action relating to proprietary medicinal products [1987] OJ L15/36

Regulation 1768/92 concerning the creation of a supplementary protection certificate for medicinal products [1992] OJ L182/1

Regulation 2309/1993 laying down Community procedures for the authorisation and supervision of medicinal products for human and veterinary use and establishing a European Agency for the Evaluation of Medicinal Products [1993] OJ L214/1

Directive 2001/83/EC on the Community code relating to medicinal products for human use [2004] OJ L311/67

Regulation 726/04 laying down Community procedures for the authorisation and supervision of medicinal products for human and veterinary use and establishing the European Medicines Agency [2004] OJ L136/1

Regulation 1901/2006 on medicinal products for paediatric use [2004] OJ L378/1

Regulation 469/2009 concerning the supplementary protection certificate for medicinal products [2009] OJ L151/1

Publisher's Note Springer Nature remains neutral with regard to jurisdictional claims in published maps and institutional affiliations. 